ment Exchange Service put those seeking employment into touch with would-be employers. But most of the success of official planning will depend not so much on office background but on the character and personality of the individuals who operate the scheme; they should themselves be specially selected, and should have understanding of human beings, aptitude for interviewing, and some knowledge of industry. The Civil Resettlement Units of the Army, set up in May of this year, help repatiliated prisoners of war discharged or released from the service. They have already done much to prevent psychiatric casualties in the changeover period. The scheme is voluntary, but has been well supported; particular attention is paid by experienced psychiatrists to the needs, and fears, of the individual; simple schemes of vocational guidance of different types have been instituted; the officers who staff these Units are themselves wellinformed as to the needs of local factories; and they are accustomed to man management. It is good to know that the medical profession has played a leading part in this venture.

Only a small proportion of ex-servicemen present problems in mental health during the resettlement phase. The majority appear to be returning to peace-time work with little trouble. It would be a mistake to assume, for example, that every exprisoner of war is a potential patient for the psychiatrist, or that the majority of returning servicemen are unhappy or depressed by civil life. But difficult cases are occurring regularly, and in organizations where industrial medical officers are established there is much scope for a new type of preventive medicine. Pre-placement medical examination is an essential part of industrial medical practice and should include all those returning from service with the Forces, no matter what their job is to be. There is already evidence that these examinations reduce labour wastage and increase industrial efficiency and at the same time decrease absence due to sickness. To help him the doctor in the factory should be provided by the Ministry of Labour with the relevant health history and, in the case of disabled workers, with the report and recommendations of the Disablement Rehabilitation Officer-the DRO. This information will naturally be confidential and not for disclosure-except in so far as the patient may agree-to any member of the management. Health defects such as bad teeth or defective vision may be found to need early remedy; so there is an opportunity to see that curative treatment is provided. Reports to management following examination must be short and to the point; their value will depend on the doctor's degree of knowledge of the different occupations available. In the personnel or labour officer with understanding the medical officer has an ally whose value cannot be overestimated; he can well implement recommendations regarding shorter hours, for example, or instructions to the canteen manager concerning diet. Job allocation based on simple job analysis is not difficult and most men fit readily into broad groups. Much of the value of the first examination is wasted if there is no follow-up system, and in this respect the help of a good nurse is essential. In large firms the doctor could well have a trained social worker on his staff. Follow-up is obviously more important in cases where there has been doubt as to physical and mental stamina; many ex-prisoners of war, for example, will need special supervision for some time to come. Follow-up must include interview and, if necessary, re-examination; progress reports should be obtained from the man's manager, foreman, or supervisor; the man should be studied at work; and it is important to find out his reactions to the job, to his mates, and to 'the firm.' If these things are well done the doctor in industry can contribute much to that part of the problem which deals with resettlement in employment; by doing so he can add to the prestige of industrial medicine in no uncertain manner.

\section{DUST AND LUNG DISEASE}

In 1923 Collis drew attention to the fact that the iron oxide inhaled by haematite iron ore miners caused shadows in the skiagrams of their chests. ${ }^{1}$ Since then McLaughlin and others have described the changes occurring in electric-arc welders and silver polishers. ${ }^{2}{ }^{3}$ It is curious, however, that the only necropsy report on these lungs continues to be that by Enzer and Sander ${ }^{4}$ who showed that while the perivascular and peribronchial lymphatic spaces were packed with iron oxide dust there was no fibrosis in the lungs. Prendergrass and Leopold ${ }^{5}$ have recently suggested that this form of dust disease should be called 'Benign Pneumokoniosis,' and while this is a good term in contrasting it with other forms of dust disease, it must be strongly stressed that the lung cannot become a physiological dust trap and yet retain its normal structure and function. It would seem probable that heroic quantities of any dust, no matter how innocuous they might be in small concentrations, would in time overwhelm the defences of the lung and accumulate in such amount as to impair function. Such a form of lung disease would obviously be due to causes of a mechanical nature-the physical presence of large amounts of inert foreign material. There is a tendency to disregard this group of diseases since any disability is slow to develop. But just as a hundred years ago the necessity for drains was discussed and now is taken for granted, it is to be hoped that within a hundred years from now the fact that ventilation can prevent these diseases will be taken for granted too, and that they will fade into medical history as a thing of the past.

Not all dusts, however, are benign. Some, such as arsenic, may give rise to carcinoma; others, such as cotton (byssinosis) and platinum may give rise to asthmatic conditions. Still others, such as manganese, beryllium, osmium and bagasse may

\footnotetext{
1 Proc. roy. Soc. Med., 1923, 16, 85.

2 Lancet, 1936, 1, 171.

4 J. industr. Hyg., 1938, 20, 333.

3 lbid., 1945, 1, 337.
} 
give rise to acute inflammatory conditions in the lungs or bronchioles, while chronic inflammation may arise from exposure to the dusts of hay ('farmer's lung'), bagasse and vanadium, among many other substances. Nevertheless, far the most important dust in industry is that resulting from silica, and a great deal of work is still needed to explain the exact means by which changes in the lung caused by this substance are brought about. The report of experimental studies on chronic pulmonary disease in South Wales coalminers by King, Belt and Nagelschmidt recently published by the Medical Research Council, ${ }^{1}$ and reviewed on another page, throws considerable light on the problem. They uphold the solubility theory of silicosis first propounded in 1932 by Kettle ${ }^{2}$ when he found that the coating of a previously harmful quartz dust with an impervious layer of iron oxide rendered it quite innocuous when introduced into the lungs of guinea-pigs; and they discard the idea suggested by Peacock in $1860^{3}$ and Greenhorn in $1865^{4}$ that the fibrous reaction was scar tissue resulting from the grains of sand and their abrasive action on the soft alveolar and lymphatic tissues of the lung. Doubt was first thrown on this latter theory in 1923, when Gardner ${ }^{5}$ published the results of his classic experiment with a dust of finely divided carborundum (silicon carbide) which failed to produce silicosis despite the sharp-edged nature of its particles.

Belt and King ${ }^{1}$ show that when silica dust is introduced into the lung, it is first engulfed in phagocytes, and so long as these cells remain intact there is no reaction in the surrounding lung tissue. The liberation of small amounts of silicic acid within the cell probably tends to preserve the cell membranes intact and fibrosis will not result, unless an acute inflammatory reaction supervenes, either from fortuitous causes or as a result of silicic acid escaping from the koniophages. If this happens an extensive acute inflammatory process results which goes on to carnification which organizes with the heavy nodular reticular fibrosis of silicosis. This theory places major importance upon the relative solubility of the silica, and as $\mathrm{King}^{1}$ has shown the apparent solubility of silica is depressed by certain substances, notably by aluminium, iron shale and certain silicates, though certain other silicates, among which asbestos is outstanding, seem to have tibrogenic powers themselves. Belt and King summarized by saying that the tissue reaction of silica is not always a simple matter of impact of silica on living cells but entails an interplay of adjuvant and antidotal factors; some of these, like the adjuvant effect of tubercle in human silicosis and the antidotal effect of aluminium, are known, while others, especially in experimental pneumokoniosis, are unknown and are not amenable to rigid control in animal dusting experiments.

The most surprising finding, however, is that while all the South Wales dusts have low silica solubilities, anthracite coals depress the silica solubility of quartz markedly more than do bituminous and steam coals, yet the incidence of severe pneumokoniosis is greater in anthracite miners than

1 Spec. Rep. Ser. Med. Res. Counc., 1945, No. 250.

J. Path Bact. Med. Res. Coun

Trans. path. Soc., Lond., 1860, 12, 36

Amer. Rev. Tuberc., 1923, 7, 344 in the bituminous or steam coalminers. The low solubility of the South Wales dusts in general would imply a low toxicity, yet many of them are pathogenic and the anthracite ones highly toxic. King suggests that the low solubilities may be related to the release, from other components of the dust, of aluminium, which may form a protective coating area over the free silica particles. Within the alveolar spaces, and in the lymph tissues, the releasable aluminium may, however, eventually disappear from the sandstone dusts and from the particles of free silica, leaving them finally exposed to the inter- and intra-cellular fluid. Thus there may be produced in the lung mineral material from which all the releasable aluminium has been leached, leaving it potentially more pathogenic than it was at the time of its inhalation. Mineral dusts containing higher proportions of aluminous components should be more inert, even after long residence in the lungs, and this seems to be the case, since it is recognized that the shales are less dangerous to health than the sandstones.

While ideally the way to prevent one dust disease is not to expose the worker to another, these theories support the Canadian evidence that aluminium dust will prevent silicosis. Denny, Robson and Irwin ${ }^{6}{ }_{7}$ showed that metallic aluminium dust of particle size below $5 \mu$ produced no fibrosis in rabbits' lungs and protected the animals against silicosis. On the other hand, Belt and King ${ }^{8}$ repeated the experiment in rats and found that the lungs of these animals treated the aluminium powder as a foreign body and formed small concretions with fibrous tissue around the particles. However, Hunter, Milton and Perry ${ }^{9}$ found no harmful effects from aluminium dust in grinders of aeroplane propellers, and Crombie, Blaisdell and MacPherson ${ }^{10}$ investigated 125 workers employed in the Pittsburgh stamp mills of the Aluminium Company of America with similar results. Nevertheless, it is difficult to conceive that alumina would not produce the same changes and mechanical effects as iron oxide, even though it is less radio-opaque, but as a result of these findings Crombie and his colleagues treated 34 silicotic miners by the daily inhalation of fine aluminium powder freshly ground from small aluminium pellets in a specially constructed mill. Daily treatment began with five-minute inhalations, which were gradually increased to 30 minutes. Some of the men received 300 treatments, but the majority only 200 . Out of 34 cases thus treated, clinical improvement in 19 was manifested by lessening or disappearance of shortness of breath, cough, pain in the chest and fatigue. In 15 cases the condition became stationary, and remained so in spite of continuous employment in silica dust throughout the treatment. The progress of the disease was assessed by means of tests of respiratory function, repeated at three-monthly intervals.

This treatment cannot be regarded as a cure for silicosis, since it cannot restore lung tissue which has undergone fibrotic change, but obviously until the engineers are able to suppress dusts completely it must be used in increasing trials in attempts to prevent the onset of this disease. It is to be hoped, therefore, that such trials will not be impeded by the fact that the Canadians have patented the process.

6 Canad. med. Ass. J., 1939, 40, 213.

7 Industr. Med., 1939, 8, 133.

9 Brit. J. Bact., 1943, 55, 69.

10 Canad. med. Ass. J., 1944, 50, 318. 